\title{
Conflicting phylogenetic signals in plastomes of the tribe Laureae (Lauraceae)
}

\author{
Tian-Wen Xiao ${ }^{1,2}$, Yong Xu ${ }^{1,2}$, Lu Jin ${ }^{1,2}$, Tong-Jian Liu ${ }^{1}$, Haifei Yan ${ }^{1}$, Xuejun Ge ${ }^{\text {Corresp. } 1}$ \\ ${ }^{1}$ Guangdong Provincial Key Laboratory of Applied Botany and Key Laboratory of Plant Resources Conservation and Sustainable Utilization, South China \\ Botanical Garden, Chinese Academy of Sciences, Guangzhou, Guangdong, People's Republic of China \\ University of Chinese Academy of Sciences, Beijing, People's Republic of China \\ Corresponding Author: Xuejun Ge \\ Email address: xjge@scbg.ac.cn
}

Background. Gene tree discordance is common in phylogenetic analyses. Many phylogenetic studies have excluded non-coding regions of the plastome without evaluating their impact on tree topology. In general, plastid loci have often been treated as a single unit, and tree discordance among these loci has seldom been examined. Using samples of Laureae (Lauraceae) plastomes, we explored plastome variation among the tribe, examined the influence of non-coding regions on tree topology, and quantified intra-plastome conflict.

Results. We found that the plastomes of Laureae have low inter-specific variation and are highly similar in structure, size, and gene content. Laureae was divided into three groups, subclades I, II and III. The inclusion of non-coding regions changed the phylogenetic relationship among the three subclades. Topologies based on coding and non-coding regions were largely congruent except for the relationship among subclades I, II and III. By measuring the distribution of phylogenetic signal across loci that supported different topologies, we found that nine loci (two coding regions, two introns and five intergenic spacers) played a critical role at the contentious node.

Conclusions. Our results suggest that subclade III and subclade II are successively sister to subclade I. Conflicting phylogenetic signals exist between coding and non-coding regions of Laureae plastomes. Our study highlights the importance of evaluating the influence of non-coding regions on tree topology and emphasizes the necessity of examining discordance among different plastid loci in phylogenetic studies. 
1 Conflicting phylogenetic signals in plastomes of the tribe Laureae (Lauraceae)

2 Tian-Wen Xiao ${ }^{1,2}$, Yong Xu ${ }^{1,2}$, Lu Jin $^{1,2}$, Tong-Jian Liu ${ }^{1}$, Hai-Fei Yan ${ }^{1}$, Xue-Jun Ge ${ }^{1}$

3

$4 \quad{ }^{1}$ Guangdong Provincial Key Laboratory of Applied Botany and Key Laboratory of Plant Resources

5 Conservation and Sustainable Utilization, South China Botanical Garden, Chinese Academy of Sciences,

6 Guangzhou, Guangdong, China.

$7 \quad{ }^{2}$ University of Chinese Academy of Sciences, Beijing, China

8

9

10 Corresponding author:

11 Xue-Jun Ge

12 Email address: xjge@sscbg.ac.cn

13

14 ORCID:

15 Xue-Jun Ge: orcid.org/0000-0002-5008-9475

16 Tian-Wen Xiao: orcid.org/0000-0002-7479-7089

17 
18 Abstract

19 Background. Gene tree discordance is common in phylogenetic analyses. Many phylogenetic studies have excluded non-coding regions of the plastome without evaluating their impact on tree topology. In general, plastid loci have often been treated as a single unit, and tree discordance among these loci has seldom been examined. Using samples of Laureae (Lauraceae) plastomes, we explored plastome variation among the tribe, examined the influence of non-coding regions on tree topology, and quantified intra-plastome conflict.

Results. We found that the plastomes of Laureae have low inter-specific variation and are highly similar in structure, size, and gene content. Laureae was divided into three groups, subclades I, II and III. The inclusion of non-coding regions changed the phylogenetic relationship among the three subclades. Topologies based on coding and non-coding regions were largely congruent except for the relationship among subclades I, II and III. By measuring the distribution of phylogenetic signal across loci that supported different topologies, we found that nine loci (two coding regions, two introns and five intergenic spacers) played a critical role at the contentious node.

Conclusions. Our results suggest that subclade III and subclade II are successively sister to subclade I. Conflicting phylogenetic signals exist between coding and non-coding regions of Laureae plastomes. Our study highlights the importance of evaluating the influence of noncoding regions on tree topology and emphasizes the necessity of examining discordance among different plastid loci in phylogenetic studies. 


\section{Introduction}

41 Gene tree discordance is relatively common in phylogenomic studies. The conflicts can be caused by biological factors like incomplete lineage sorting (ILS), hybridization, horizontal gene transfer, gene loss, and gene duplication (Maddison, 1997; Sun et al., 2015; Gonçalves et al., 2019; Sato et al., 2019). Most relevant studies have focused on incongruent tree topologies among different genomic compartments (Sun et al., 2015; Zhao et al., 2016; Walker et al., 2019) because these genes have evolved independently and their gene tree topologies have been 
61 phylogenomic conflict (e.g., Stegemann et al., 2003; Smith, 2014; Wysocki et al., 2015; Piot et

62 al., 2018; Saarela et al., 2018; Foster, Henwood \& Ho, 2018). Aside from biological factors,

63 non-biological factors (e.g., outlier genes, uninformative loci, and gaps) may cause conflict as

64 well. For example, Duvall, Burke \& Clark (2020) found that alternative topologies arose from

65 alignment gaps. Given that most studies assume no conflict and treat the plastome as a single

66 unit, taking biological and non-biological factors into consideration and quantifying the extent of

67 conflict among different plastid loci is of great importance (Wolfe \& Randle, 2004).

68 Owing to the rapid development of next-generation sequencing (NGS), more plastomes are

69 becoming available at a reasonable cost, driving advances in phylogenomics and promoting a

70 more comprehensive understanding of plant evolution (Li et al., 2019). Phylogenetic

71 relationships among Lauraceae (Song et al., 2017), as well as many other groups (e.g., Eserman

72 et al., 2014; Barrett et al., 2016), have been well resolved using plastome data. In phylogenomic

73 studies of plastomes (Guo et al., 2017; Gonçalves et al., 2019; Xu et al., 2019; Li et al., 2019),

74 plastome coding genes have generally been used, and non-coding regions have been excluded.

75 Only a few studies have noted the potential impact of non-coding regions on tree topology.

76 Parks, Cronn \& Liston (2009) revealed that the phylogenetic position of Pinus albicaulis

77 Engelm. based on complete plastomes differed from that based on exon sequences. A similar

78 situation also occurred for phylogenetic relationships within Rubiaceae (Wikström, Bremer \&

79 Rydin, 2020), suggesting that there were conflicting phylogenetic signals between coding- and

80 non-coding regions. Because tree topology is the foundation of comparative studies that infer

81 biogeographic history, phylogenetic diversity and other evolutionary patterns (Walker et al., 
82

2019), the influence of non-coding regions on phylogenetic inference should be evaluated.

$$
\text { Both ILS and hybridization are at play in tree species, which generally have high rates of }
$$
outcrossing and large population sizes (Petit \& Hampe, 2006; Crowl et al., 2019). Interspecific hybrids have been described in Persea (tribe Perseeae, sister to tribe Cinnamomeae and tribe Laureae), Cinnamomum and Aiouea (tribe Cinnamomeae) (van der Werff, 1984; Rohwer et al., 2019). These processes are perhaps also problematic in Laureae. When combined, such biological processes may make accurate inference of evolutionary relationships in Laureae difficult. Unfortunately, previous phylogenomic studies of Laureae have ignored potential conflicts among different plastid loci and the underlying processes that may have generated them (Zhao et al., 2018; Song et al., 2019; Tian, Ye \& Song, 2019). These characteristics make Laureae an ideal group in which to explore intra-plastome conflict and its influence on phylogenetic inference.

Tribe Laureae, a species-rich group in the family Lauraceae, is phylogenetically sister to tribe Cinnamomeae (Song et al., 2019). It comprises approximately 500 species and 10 genera: Actinodaphne, Adenodaphne, Dodecadenia, Iteadaphne, Laurus, Lindera, Litsea, Neolitsea, Parasassafras and Sinosassafras (van der Werff \& Richter, 1996; Chanderbali, van der Werff \& Renner, 2001; Li et al., 2004; Li et al., 2008b). Species of this tribe are evergreen or deciduous and usually occur in the form of trees or shrubs (Li et al., 2008a). Their distribution ranges from the Mediterranean region, Asia, and Oceania to North America (Li et al., 2004). Some members of Laureae have great ecological and economic value. For example, Neolitsea sericea (B1.) Koidz. is a dominant species found in various evergreen and deciduous broadleaf mixed forests 
103

104

105

106

and in evergreen broadleaf forests (Wang et al., 2009), and Laurus nobilis L. has been used in remedies for centuries (Nayak et al., 2006).

Although Laureae is monophyletic, generic delimitation within this tribe remains unclear (Kostermans, 1957; Hutchinson, 1964; Li et al., 2008b). Adenodaphne, endemic to New Caledonia, is closely related to Litsea (Chanderbali, van der Werff \& Renner, 2001). However, morphological confusion still exists between this genus and Litsea, meaning that their distinctiveness and the monophyly of Adenodaphne require further study (Chanderbali, van der Werff \& Renner, 2001). Actinodaphne is polyphyletic and closely related to the monophyletic genus Neolitsea (Li et al., 2007; Li et al., 2008b; Fijridiyanto \& Murakami, 2009a, 2009b). Although Fijridiyanto \& Murakami (2009a, 2009b) argued that Actinodaphne was monophyletic, the species of Actinodaphne sampled in their analyses were totally different from those sampled in Li et al. (2007) and Li et al. (2008b). Furthermore, Lindera and Litsea have been shown to be polyphyletic, with Dodecadenia, Iteadaphne, Laurus, Parasassafras and Sinosassafras nested within them (Li et al., 2004; Li et al., 2008b). Liu et al. (2017) used three plastid barcode loci combined with the internal transcribed spacer (ITS) region for species identification and found that the Laureae tree was polytomic. Despite these efforts, phylogenetic relationships among and within these genera have been poorly resolved based on molecular markers like the ITS, the external transcribed spacer (ETS), matK, trnL-F and trnH-psbA. Compared with these molecular markers, complete plastomes have better performance at the species level within Laureae, although generic delimitation still remains unclear due to limited taxon sampling (Zhao et al., 2018; Song et al., 2019; Tian, Ye \& Song, 2019). 
124

125

126

127

128

129

130

131

132

133

134

135

136

137

138

139

140

141

142

143

144

Thirty-five plastomes representing 28 species and six genera of Laureae have been published (Table S1). Compared with the vast diversity of Laureae, the published plastome data for this group are relatively limited. Hence, we now report 12 newly sequenced plastomes (Table 1) and combine them with existing plastomes to address three primary goals: (1) reinvestigation of phylogenetic relationships within Laureae; (2) examination of conflict between coding and noncoding regions; and (3) quantification of conflicts among different plastid loci.

\section{Methods}

\section{Plant materials, DNA extraction and genome sequencing}

Materials from 12 species in five genera (Actinodaphne obovata (Nees) Bl., Iteadaphne caudata (Nees) H. W. Li, Lindera erythrocarpa Makino, Litsea acutivena Hay., L. elongata (Wall. ex Nees) Benth. et Hook. f., L. glutinosa (Lour.) C. B. Rob., L. dilleniifolia P. Y. Pai et P. H. Huang, L. mollis Hemsl., L. monopetala (Roxb.) Pers., L. pungens Hemsl., L. szemaois (H. Liu) J. Li et H.W. Li, and Neolitsea pallens (D. Don) Momiy. et H. Hara) (tribe Laureae, Lauraceae) were collected and identified by the authors (Table 1). Voucher specimens were deposited in the herbarium of the South China Botanical Garden (IBSC) at the Chinese Academy of Sciences. No specific permissions were required for the relevant locations and activities. Including the plastomes downloaded from GenBank and the Lauraceae Chloroplast Genome Database (LCGDB, https://lcgdb.wordpress.com) (Table S1), this study included 47 Laureae plastomes, representing seven genera and all subclades identified by Song et al. (2019). Twelve plastomes from other tribes were also downloaded (Table S1). 
145 Genomic DNA was extracted from silica-gel-dried leaf tissue using the cetyl trimethyl

146 ammonium bromide (CTAB) method (Doyle \& Doyle, 1987). The yields of genomic DNA

147 extracts were quantified by fluorometric quantification on a Qubit instrument (Invitrogen,

148 Carlsbad, California, USA) using the dsDNA HS kit, and the DNA size distribution was assessed

149 visually on a $1 \%$ agarose gel. DNA libraries with an average insert size of $270 \mathrm{bp}$ were prepared

150

by the Beijing Genomics Institute (BGI, Shenzhen, China). Paired-end reads of $2 \times 151 \mathrm{bp}$ were

151 generated on the Illumina $X$ ten sequencing system (Illumina Inc.).

152

153

154

Usadel, 2014), generating approximately $3 \mathrm{~Gb}$ of high-quality clean reads per sample. The clean reads were analyzed for quality control with FastQC (Andrews, 2010) and then used to assemble plastomes with NOVOPlasty v2.7.2 (Dierckxsens, Mardulyn \& Smits, 2016). To guarantee assembly quality, clean reads were mapped to the assembled plastid genomes using the BurrowsWheeler Aligner (BWA 0.7.17-r1188 (Li \& Durbin, 2010)) and samtools 1.9 (Li et al., 2009), and were visually checked in Geneious Prime 2019.1.

Geneious Prime when necessary. Plastomes were submitted to GenBank (MN274947, MN428456-MN428466). Maps of all 12 plastomes were drawn using the 
166

167

168

169

170

171

172

173

174

175

176

177

178

179

180

181

182

183

184

185

186

sequenced plastomes is presented in Table 2.

To illustrate interspecific sequence variation within Laureae, plastomes of A. obovata, I.

caudata, Laurus nobilis (KY085912), Lindera erythrocarpa, Litsea acutivena, N. pallens and

Parasassafras confertiflorum (Meisn.) D. G. Long (MH729378) were aligned using MAFFT

(Katoh \& Standley, 2013) with default settings. Sequence identity was plotted with the mVISTA program using the LAGAN mode (Frazer et al., 2004), with Lindera glauca (Siebold et Zucc.)

B1. (MF188124) as a reference.

3

\section{Phylogenetic reconstruction and tests for selection}

To evaluate potential conflicts, phylogenetic trees were constructed using maximum likelihood

(ML) methods based on six datasets: (1) complete plastome (CP), (2) coding regions (CDS), (3)

non-coding regions (non-CDS), (4) large single copy region (LSC), (5) small single copy region

(SSC), and (6) one inverted repeat region (IR).

Sequences were aligned using MAFFT with default settings and manually edited with BioEdit v7.2.5 (Hall, 1999) when necessary. The best-fitting DNA substitution models for the six unpartitioned datasets were selected using ModelTest-NG (Darriba et al., 2020) under the corrected Akaike Information Critierion (AICc). The aligned sequences and selected DNA substitution models were used for ML analyses, and ML trees were constructed using RAxMLNG (Kozlov et al., 2019). We also implemented a partitioning strategy on two datasets, the CP with one IR region removed (CP-reduced) and CDS (configuration details shown in Supplemental File 1). The optimal partitioning schemes for each dataset were inferred with 
187 PartitionFinder 2 (Lanfear et al., 2016), and the optimal partitioning schemes, and nucleotide

188 substitution models for each partition were used for ML analyses in RAxML-NG.

189 Because gaps can affect tree topology (Duvall, Burke \& Clark, 2020), we also performed the

190 following analysis based on the CP dataset. 'Mask Alignment' in Geneious Prime was used to

191 strip the gaps from the MAFFT alignment, with the threshold set to 0 (no gaps), $2 \%, 10 \%, 20 \%$,

$19250 \%$ or $75 \%$. The resulting alignments were used to infer ML trees in RAxML-NG.

193 Positive selection on plastid coding genes has the potential to bias phylogenies (e.g., Piot et

194 al., 2018; Saarela et al., 2018), and we therefore performed positive selection tests using

195 CODEML in PAML 4.9j (Yang, 2007). Coding genes were extracted and aligned in Geneious

196 Prime using MAFFT, stop codons were removed manually, and the aligned sequences were

converted to PAML format. Because site models allow dN/dS ratio to vary among different sites, we

implemented M0, M1a, M2a, M3, M7 and M8 to identify positively selected sites. Likelihood ratio tests

(LRTs) were performed using pchisq function in R 3.6.2 (R Core Team, 2018) to test if there was

significant difference between models (M0 vs M3, M2a vs M1a, M8 vs M7). We manually

deleted positively selected sites when LTRs was significant (M2a vs M1a and/or M8 vs M7 with

$p$ value less than 0.05$)$. Coding gene alignments with positively selected sites removed were

concatenated (CDS-reduced dataset), and used for ML tree inference to examine whether

positive selection can bias phylogeny or not.

205

206

\section{Node support investigation and tree topology tests}

Because gene contents were not identical among Cryptocaryeae, Cassytha, Caryodaphnopsis, 
208

209

210

211

212

213

214

215

216

217

218

219

220

221

222

223

224

225

226

227

228

Neocinnamomum and other clades, the following analyses were performed using a dataset from which six plastomes had been removed (Beilschmiedia pauciflora H. W. Li, Caryodaphnopsis malipoensis Bing Liu et Y. Yang, Cassytha filiformis L., Cryptocarya chinensis (Hance) Hemsl. and Eusideroxylon zwageri Teijsm. et Binn.).

We extracted all loci (coding regions, introns, tRNA, rRNA and intergenic spacers) using a python script (Jin, 2019) and aligned them using MAFFT with default settings. These alignments were used to infer gene trees by rapid bootstrap analyses (option -f a) in RAxML (Stamatakis, 2014) with the GTRGAMMA model. The number of bootstrap replicates was set to 1000, as

Simmons \& Kessenich (2019) have suggested that fewer replicates may be insufficient to find the optimal gene tree topology. The best-scoring ML trees were used to estimate the species tree with local posterior probability (LPP) (Sayyari \& Mirarab, 2016) in ASTRAL III (Zhang et al., 2018).

We performed constrained maximum likelihood analyses in IQ-TREE (Nguyen et al., 2014) to obtain the ML trees that supported different topologies. To understand which loci supported the alternative topologies, we calculated site-wise log-likelihood values for each topology in RAxML using option “-f G”. After obtaining site-wise $\operatorname{lnL}$ differences, we converted site-wise differences to locus-wise $\operatorname{lnL}$ differences $(\Delta \operatorname{lnL})$ in $\mathrm{R}$ 3.6.2. The $\ln L$ differences were plotted against each locus using ggplot2 (Wickham, 2016). It has been suggested that loci with an absolute $\Delta \operatorname{lnL}>2$ are statistically significant (Edwards, 1984). Therefore, we conducted separate ML analyses on datasets from which these loci (absolute $\Delta \operatorname{lnL}>2$ ) had been removed to test whether small subsets of sequence matrices determined tree topology (Shen, Hittinger \& Rokas, 
229

230

231

232

233

234

235

236

237

238

239

240

241

242

243

244

245

246

247

2017).

The Kishino-Hasegawa test (KH test) (Kishino \& Hasegawa, 1989), Shimodaira-Hasegawa test (SH test) (Shimodaira \& Hasegawa, 1999) and Approximately-Unbiased test (AU test)

(Shimodaira, 2002) were used in IQ-TREE to assess the statistical significance of incongruence based on complete plastomes (including only one copy of the IR regions). We specified 10,000 RELL (resampling of estimated log-likelihoods) replicates for the topological tests.

\section{Results}

\section{Plastome features of Laureae}

The sizes of the 12 newly generated Laureae plastid genomes ranged from 152,132 bp (Litsea szemaois) to 152,916 bp (Lindera erythrocarpa) (Table 2), similar to previously published Laureae plastomes (152,211-153,011 bp, Table S1). All had a typical quadripartite structure and were assembled into a single, circular and double-stranded DNA sequence (Fig. 1). The length of the LSC, SSC and IR regions ranged from 93,119 bp (Litsea szemaois) to 93,921 bp (Lindera erythrocarpa), 18,796 bp (N. pallens) to 18,936 bp (Litsea mollis), and 20,057 bp (A. obovata) to 20,144 bp (I. caudata), respectively, with little variation in size (Table 2). The overall GC contents ranged from $39.1 \%$ to $39.2 \%$. GC content was unequally distributed within the plastomes; it was highest in IR regions (44.4-44.5\%), moderate in LSC regions (37.9-38.1\%), and lowest in SSC regions (33.8-34.0\%, Table 2).

The 12 newly sequenced plastomes contained 112 single-copy genes: 78 protein-coding genes, 30 tRNA genes, and 4 rRNA genes (Table 2 and Table S2). Sixteen genes had one intron, 
250

251

252

253

254

255

256

257

258

259

260

261

262

263

264

265

266

267

268

269

270

and two genes had two introns. There were 13 duplicated genes in the IR regions (Table S2), and rps 12, ycf1, and ycf2 were partly duplicated in the IR regions (Fig. 1).

\section{Phylogenetic reconstruction and positive selection tests}

The GTR $+\mathrm{I}+\mathrm{G} 4$ model was selected for the six unpartitioned datasets (CP, CDS, non-CDS, LSC, SSC and IR). Perseeae was sister to Cinnamomeae and Laureae (Figs. 2 and S1-S5). All the ML trees indicated the monophyly of Laureae with high bootstrap (BS) support values (99-100\%, Figs. 2 and S1-S4), except for the ML tree based on the IR region (71\%, Fig. S5). This result was caused by the low variability of the IR region (Fig. S6). In the five ML trees (Figs. 2 and S1-S4), Laureae was divided into three groups. Subclade I included Lindera communis Hemsl., L. glauca and L. nacusua (D. Don) Merr.; subclade II included Laurus azorica (Seub.) Franco, L. nobilis, Lindera megaphylla Hemsl., Litsea acutivena, L. glutinosa, L. monopetala and L. pungens; and subclade III included the other Laureae species used in the study. In subclade I, Lindera glauca was sister to L. communis and L. nacusua. In subclade II, Laurus was sister to Litsea acutivena, L. glutinosa and Lindera megaphylla, and the position of Litsea pungens was unstable (Figs. 2 and S1-S4). Litsea monopetala (LAU00063) was embedded within three samples of Litsea glutinosa in subclade II, highlighting the necessity of re-identification for $L$. monopetala (LAU00063). Topologies within subclade III based on different datasets were largely congruent (Figs. 2 and S1-S4). In subclade III, samples of Litsea, together with Lindera obtusiloba B1., were monophyletic. Lindera erythrocarpa, L. latifolia Hook. f., L. metcalfiana Allen and L. robusta (Allen) Tsui were monophyletic as well. Lindera aggregata, L. chunii 
271

272

273

274

275

276

277

278

279

280

281

282

283

284

285

286

287

288

289

290

291

Merr., L. fragrans Oliv., L. limprichtii H. Wink1., L. pulcherrima (Wall.) Benth., L. supracostata

Lec., L. thomsonii Allen and L. thomsonii var. vernayana (Allen) H.P. Tsui formed a well-

supported clade. Neolitsea was closer to Actinodaphne than to other Laureae species.

Subclade II was sister to subclade I based on four unpartitioned datasets (CP, non-CDS, LSC, SSC; Figs. 2 and S2-S4, respectively). However, subclade II was sister to subclade III rather than subclade I based on the unpartitioned CDS dataset (Fig. S1). Both topologies were strongly supported. The sister relationship of subclades I and II was supported in the ML tree based on partitioned plastomes (one IR removed, CP-reduced dataset; Fig. S7), and subclade II was sister to subclade III in the ML tree based on the partitioned CDS dataset (Fig. S8), indicating that our results were robust to different partitioning schemes.

The sister relationship of subclades I and II (BS values ranging from $80 \%$ to $92 \%$ ) was consistently revealed even as the percentage of gaps increased (Table S3), indicating that gaps had no impact on our tree topology. Positively selected sites were detected in 27 coding genes (Table S4). The ML tree based on CDS-reduced dataset supported a sister relationship of subclades II and III (Fig. S9), consistent with ML trees based on CDS dataset (Figs. S1 and S8), suggesting that positive selection did not affect the relationship of the three subclades.

\section{Investigating incongruent nodes and differences in tree topology}

The tree topology inferred from ASTRAL III (Fig. 3) was largely congruent with that of the ML trees (Figs. 2 and S1-S4), except that the former showed a sister relationship of subclade I and subclade III. We performed constrained maximum likelihood analyses in IQ-TREE and obtained 
292

293

294

295

296

297

three suboptimal ML trees that supported the subclade II-subclade I (called T1 hereafter), subclade II-subclade III (T2) and subclade I-subclade III (T3) affinities. We extracted 243 loci and assessed how each locus supported one of the three topologies by examining the gene-wise log-likelihoods (Fig. 4). T1 was strongly supported by six loci (rpoCl intron, trnG-trnfM, ndhA intron, psaJ-rpl33, rpl2-rpl23 and petN-psbM; absolute $\Delta \operatorname{lnL}>2$ ); T2 was strongly supported by three loci ( $p s a B, \operatorname{trn} S-y c f 3$ and $y c f 2$; absolute $\Delta \operatorname{lnL}>2)$; and T3 was moderately supported by one locus ( $\operatorname{lpP} P$ intron1; absolute $\Delta \operatorname{lnL}>1$ and $<2)($ Table S5). The sum of absolute $\Delta \operatorname{lnL}$ of $\mathrm{T} 1$ was higher than that of T2 and T3 (Fig. 4), suggesting that our data support the topology of T1 rather than T2 or T3. After the removal of six loci (rpoC1 intron, $\operatorname{trn} G$-trnfM, $n d h A$ intron, $p s a J-$ rpl33, rpl2-rpl23 and pet N-psbM), a sister relationship of subclade II and subclade III was revealed (Fig. S10). After the removal of three loci ( $p s a B$, trnS-ycf3, and $y c f 2)$, subclade II was sister to subclade I (Fig. S11). These results underscore the decisive role played by small subsets of loci in phylogenetic inference.

The topological tests showed that T2 did not differ significantly from T1 ( $p>0.05$, Table S6). T3 was statistically rejected by the KH and AU tests $(p<0.05)$ but not by the ShimodairaHasegawa $(\mathrm{SH})$ test $(p=0.0505)$. That T3 was rejected according to the $\mathrm{KH}$ and AU tests suggests that the sister relationship between subclades I and III may be misleading.

\section{Discussion}

\section{Plastome features}

It has been noted that most plastid genomes of land plants and algae range from 120 to 160 
313 kilobase pairs $(\mathrm{kb})$ in length (Palmer, 1985). In this study, the plastid genome sizes of 12 species

314 from five Laureae genera ranged from $152,132 \mathrm{bp}$ to $152,916 \mathrm{bp}$, indicating that plastid genome

315 size was conserved within Laureae. GC content was highest in the IR region rather than in the

316 single copy regions, owing to the presence of a ribosomal RNA gene cluster in the IR region,

317 consistent with a previous study (Huotari \& Korpelainen, 2012). GC contents of the IR, LSC and

318 SSC regions of the newly sequenced plastomes were identical to those of nine Lindera species

319 studied earlier (Zhao et al., 2018). In contrast to the gene losses recognized in several Lauraceae

320 lineages (Song et al., 2017), our analysis revealed that gene content among Laureae was highly

321 conserved. Song et al. (2017) suggested that plastome contraction in Lauraceae was largely

322 driven by fragment loss events in the IR regions. In our study, we found no gene loss among

323 Laureae plastomes.

324

325

326

327 and 3). In previous work, Actinodaphne and Neolitsea were resolved as monophyletic groups based on matK, ITS and rpb2 (Fijridiyanto \& Murakami, 2009a, 2009b), but Actinodaphne was not a monophyletic group based on complete plastid genomes (Song et al., 2019). In this study, the non-monophyletic status of Actinodaphne was supported. The conclusion of Actinodaphne monophyly may have been caused by sampling bias in previous studies (Fijridiyanto \& 
334 Murakami, 2009b, 2009a). The monophyly of Neolitsea can be neither rejected nor supported in

335 the present study. Actinodaphne cupularis (Hemsl.) Gamble was grouped with Neolitsea

336 oblongifolia Merr. et Chun, N. pallens and N. chui Merr. with low bootstrap support (54\%; Fig.

337 2), and sampling of Neolitsea and related genera was limited. Lindera and Litsea were

338

339

340

341

342

343

344

345

346

polyphyletic in our analysis, consistent with previous studies (Li et al., 2008b; Fijridiyanto \&

Murakami, 2009b). The phylogenetic position of $P$. confertiflorum was unresolved based on ETS

and ITS (Li et al., 2008b), and the ambiguity of its position still remains, despite the integration

of complete plastid genomes in our analysis and a previous study (Liao, Ye \& Song, 2018).

Subclade III was sister to subclade I and II in our study, consistent with previous analyses

(Zhao et al., 2018; Song et al., 2019; Tian, Ye \& Song, 2019). The three Lindera species in

subclade I share common morphological traits, such as alternate and pinninerved leaves, a

persistent involucre, vegetative terminal buds in inflorescences and 3-merous flowers ( $\mathrm{Li}$ et al.,

2008a). However, these characters also occur in several members of the other two subclades

(e.g., Lindera benzoin (L.) B1. and Laurus nobilis), perhaps resulting from convergent and/or

parallel evolution ( $\mathrm{Li}$ et al., 2008b). These traits are not good indicators for delimiting the three

subclades of Laureae. In subclade III, the trinerved or triplinerved species of Lindera (Lindera

aggregata, L. chunii, L. fragrans, L. limprichtii, L. pulcherrima, L. supracostata, L. thomsonii

and L. thomsonii var. vernayana) formed a well-supported clade in both our study and that of

Tian, Ye \& Song (2019). However, triplinerved leaves also exist in most species of Neolitsea (Li et al., 2008b; Li et al., 2008a). Therefore, traditional morphological traits are of limited use in taxon delimitation, even within subclades of Laureae. Given the limited samples and data in our 
355

356

357

358

359

360

361

362

363

364

365

366

367

368

369

370

371

372

373

374

375

analyses, more sampling and DNA sequences are needed to further elucidate the relationships within Laureae.

\section{Phylogenetic incongruence in the plastome}

Although many studies have treated plastid protein-coding genes or the complete plastome as a single unit (e.g., Song et al., 2019; Tian, Ye \& Song, 2019), potential conflicts among sequence types (i.e., coding vs. non-coding regions) have been reported in several studies. By comparing phylogenies based on complete plastomes and coding regions (Yu et al., 2017), it was inferred that non-coding regions did not significantly influence the tree topology of Theaceae. By contrast, non-coding regions had an impact on the phylogenetic relationships of several tribes in Rubiaceae (Wikström, Bremer \& Rydin, 2020) and subtribes in Poaceae (Saarela et al., 2018). A conflicting signal between coding and non-coding regions was also reported in Leguminosae (Zhang et al., 2020). In this study, inclusion of non-coding regions altered tree topology in the tribe Laureae, suggesting the existence of a conflicting signal between coding and non-coding regions. Non-coding regions are often discarded for being uninformative, or for being misleading due to saturation at deep time scales (Foster, Henwood \& Ho, 2018). In our study, tree topologies based on coding and non-coding regions were largely congruent, except for the relationships among the three subclades (Figs. S1-S2), indicating that non-coding regions are as informative as coding regions in Laureae. Thus, it is imperative to evaluate the influence of noncoding regions on tree topology rather than treating the whole plastome as a single unit or simply excluding non-coding regions from phylogenetic analysis. 
To accommodate the conflicts among different plastid regions, a species tree was inferred

377

378

379

380

through summary coalescent analysis. It has been suggested that the coalescent method is more robust than the concatenation method when the level of ILS is high (Liu, Xi \& Davis, 2014;

Mirarab, Bayzid \& Warnow, 2014). High ILS tends to occur when the time interval between consecutive speciation events is short (Sun et al., 2015; Sato et al., 2019), and the core Lauraceae group (Perseeae, Cinnamomeae and Laureae) is thought to have undergone a rapid radiation (Chanderbali, van der Werff \& Renner, 2001; Rohwer \& Rudolph, 2005; Nie, Wen \& Sun, 2007). We therefore chose to implement the coalescent method. Nonetheless, it should be noted that, with this method, short and uninformative loci may lead to problematic gene trees and therefore result in a less accurate species tree (Xi, Liu \& Davis, 2015; Springer \& Gatesy, 2016). In our study, only nine of 243 loci (rpoCl intron, $\operatorname{trn} G$-trnf $M$, $n d h A$ intron, $p s a J-r p l 33, r p l 2$ $r p l 23$, pet $N-p s b M, p s a B, \operatorname{trnS}-y c f 3$, and $y c f 2$ ) had a strong phylogenetic signal at the contentious node. The other 234 loci with weak phylogenetic signals may have resulted in gene trees with uncertainties and led to inaccurate topology at this node.

$$
\text { Exploration of the factors that underlie conflicts in phylogenetic signals is of great }
$$
importance — but it is also challenging. Previous studies have examined whether biological and non-biological factors contribute to such conflicts (e.g., Duvall, Burke \& Clark, 2020; Zhang et al., 2020). For example, gaps have been found to cause alternate, but conflicting topologies in Poaceae (Duvall, Burke \& Clark, 2020). However, the inclusion of alignment gaps did not alter our tree topology (Table S3). Although previous studies indicated that partitioning improves phylogenetic inference (Xi et al., 2012), ML tree topologies based on partitioned and 
397

398

399

400

401

402

403

404

405

406

407

408

409

410

411

412

413

414

415

416

417

unpartitioned datasets did not differ significantly in our study. It has been suggested that plastid genes under positive selection may bias phylogenies (e.g., Piot et al., 2018; Saarela et al., 2018), however, we found that the relationship among subclades I, II and III was not affected by positively selected sites, suggesting that positive selection was not the cause of tree conflicts. In this study, the low support values and short branch lengths of the estimated species tree (Fig. 3) suggested that each locus had a significantly incongruent topology and may indicate the existence of ILS. High levels of ILS are thought to yield similar numbers of loci supporting alternative topologies (Huson et al., 2005). In our study, the numbers of loci supporting each topology were different (six for T1, three for T2, and zero for T3 after exclusion of loci with absolute $\Delta \operatorname{lnL} \leq 2$ ), suggesting that ILS may not be the primary cause of the discordance among loci. Another plausible explanation for the conflict is heteroplasmic recombination, which can occur in species with biparental plastome inheritance (Walker et al., 2019). Although heteroplasmic recombination has been reported with clear evidence in Brachypodium and Picea (Sullivan et al., 2017; Sancho et al., 2018), to our knowledge it has never been documented in Lauraceae. Based on the data reported here, it is too early to draw a firm conclusion about the causes of the conflict in phylogenetic signals. Although fully resolved phylogenies may still remain elusive based on different genomic compartments (i.e., nuclear, mitochondrial and plastid), phylogenomic studies that incorporate these compartments can provide new insights into tree discordance and its underlying causes (Koenen et al., 2020). Therefore, more genetic information (e.g., nuclear genes) will be required to solve this problem in future work. 


\section{Conclusion}

419 In summary, this study revealed that Laureae plastomes are conserved in structure, size and gene content. A conflicting phylogenetic signal was detected between coding and non-coding regions, suggesting that the plastid genome should not be treated as a single unit. ML trees based on coding and non-coding regions were largely congruent except at the contentious node, indicating that coding regions are as informative as non-coding regions and that the influence of non-coding regions on tree inference should be evaluated. We also found that small subsets of plastome loci determined the topology at specific nodes, consistent with the results of a previous study (Shen, Hittinger \& Rokas, 2017). Through quantification and analysis of intra-plastome conflicts, the sister relationship of subclade I (including Lindera communis, L. glauca and L. nacusua) and II (including Laurus azorica, L. nobilis, Lindera megaphylla, Litsea acutivena, L. glutinosa, L. monopetala and L. pungens) was supported by our study. Biological factors may contribute to the conflicts among plastid loci; however, more information is needed to determine the underlying mechanism(s).

\section{Acknowledgements}

The authors thank Yu-Ying Zhou and Chen-Xin Ma for assistance with the DNA experiments. They also thank (www.topeditsci.com) for English language editing of this manuscript.

\section{Reference}


441

442

443

444

445

446

447

448

449

450

451

452

453

454

455

456

457

458

459

460

461

462

463

464

465

466

467

468

469

470

471

472

473

474

475

476

477

478

479

480

481

Andrews S. 2010. FastQC: a quality control tool for high throughput sequence data. Available at http://www.bioinformatics.babraham.ac.uk/projects/fastqc

Barrett CF, Baker WJ, Comer JR, Conran JG, Lahmeyer SC, Leebens-Mack JH, Li J, Lim GS, Mayfield-Jones DR, Perez L, Medina J, Pires JC, Santos C, Wm. Stevenson D, Zomlefer WB, Davis JI. 2016. Plastid genomes reveal support for deep phylogenetic relationships and extensive rate variation among palms and other commelinid monocots. New Phytologist 209:855-870 DOI: 10.1111/nph.13617.

Birky CW. 1995. Uniparental inheritance of mitochondrial and chloroplast genes: mechanisms and evolution. Proceedings of the National Academy of Sciences of the United States of America 92:11331-11338 DOI: 10.1073/pnas.92.25.11331.

Bolger AM, Lohse M, Usadel B. 2014. Trimmomatic: a flexible trimmer for Illumina sequence data. Bioinformatics 30:2114-2120 DOI: 10.1093/bioinformatics/btu170.

Carbonell-Caballero J, Alonso R, Ibañez V, Terol J, Talon M, Dopazo J. 2015. A phylogenetic analysis of 34 chloroplast genomes elucidates the relationships between wild and domestic species within the genus Citrus. Molecular Biology and Evolution 32:2015-2035 DOI: 10.1093/molbev/msv082.

Chanderbali AS, van der Werff H, Renner SS. 2001. Phylogeny and historical biogeography of Lauraceae: Evidence from the chloroplast and nuclear genomes. Annals of the Missouri Botanical Garden 88:104-134 DOI: $10.2307 / 2666133$.

Crowl AA, Manos PS, McVay JD, Lemmon AR, Lemmon EM, Hipp AL. 2019. Uncovering the genomic signature of ancient introgression between white oak lineages (Quercus). New Phytologist DOI: 10.1111/nph.15842.

Darriba D, Posada D, Kozlov AM, Stamatakis A, Morel B, Flouri T, Crandall K. 2020. ModelTest-NG: A new and scalable tool for the selection of DNA and protein evolutionary models. Molecular Biology and Evolution 37:291-294 DOI: 10.1093/molbev/msz189.

Dierckxsens N, Mardulyn P, Smits G. 2016. NOVOPlasty: de novo assembly of organelle genomes from whole genome data. Nucleic Acids Research 45:e18-e18 DOI: 10.1093/nar/gkw955.

Doyle JJ, Doyle JL. 1987. A rapid DNA isolation procedure for small quantities of fresh leaf tissue. Phytochemical Bulletin 19:11-15.

Duvall MR, Burke SV, Clark DC. 2020. Plastome phylogenomics of Poaceae: alternate topologies depend on alignment gaps. Botanical Journal of the Linnean Society 192:9-20 DOI: 10.1093/botlinnean/boz060.

Edwards AWF. 1984. Likelihood. Cambridge: Cambridge University Press.

Eserman LA, Tiley GP, Jarret RL, Leebens-Mack JH, Miller RE. 2014. Phylogenetics and diversification of morning glories (tribe Ipomoeeae, Convolvulaceae) based on whole plastome sequences. American Journal of Botany 101:92-103 DOI: 10.3732/ajb.1300207.

Fijridiyanto IA, Murakami N. 2009a. Molecular systematics of Malesian Litsea Lam. and putative related genera (Lauraceae). Acta Phytotaxonomica et Geobotanica 60:1-18 DOI: 10.18942/apg.KJ00005576218.

Fijridiyanto IA, Murakami N. 2009b. Phylogeny of Litsea and related genera (Laureae-Lauraceae) based on analysis of rpb2 gene sequences. Journal of Plant Research 122:283-298 DOI: 10.1007/s10265-009-0218-8.

Foster CSP, Henwood MJ, Ho SYW. 2018. Plastome sequences and exploration of tree-space help to resolve the phylogeny of riceflowers (Thymelaeaceae: Pimelea). Molecular Phylogenetics and Evolution 127:156-167 DOI: 10.1016/j.ympev.2018.05.018.

Frazer KA, Pachter L, Poliakov A, Rubin EM, Dubchak I. 2004. VISTA: computational tools for comparative genomics. Nucleic Acids Research 32:W273-W279 DOI: 10.1093/nar/gkh458.

Peer) reviewing PDF | (2020:05:49532:2:0:NEW 3 Sep 2020) 
482

483

484

485

486

487

488

489

490

491

492

493

494

495

496

497

498

499

500

501

502

503

504

505

506

507

508

509

510

511

512

513

514

515

516

517

518

519

520

521

522

Gonçalves DJP, Simpson BB, Ortiz EM, Shimizu GH, Jansen RK. 2019. Incongruence between gene trees and species trees and phylogenetic signal variation in plastid genes. Molecular Phylogenetics and Evolution 138:219-232 DOI: 10.1016/j.ympev.2019.05.022.

Guo X, Liu J, Hao G, Zhang L, Mao K, Wang X, Zhang D, Ma T, Hu Q, Al-Shehbaz IA, Koch MA. 2017. Plastome phylogeny and early diversification of Brassicaceae. BMC Genomics 18:176 DOI: 10.1186/s12864-0173555-3.

Hall TA. 1999. BioEdit: a user-friendly biological sequence alignment editor and analysis program for Windows 95/98/NT. Nucleic Acids Symposium Series 41:95-98.

Huotari T, Korpelainen H. 2012. Complete chloroplast genome sequence of Elodea canadensis and comparative analyses with other monocot plastid genomes. Gene 508:96-105 DOI: 10.1016/j.gene.2012.07.020.

Huson DH, Klöpper T, Lockhart PJ, Steel MA. 2005. Reconstruction of reticulate networks from gene trees. In: Miyano S, Mesirov J, Kasif S, Istrail S, Pevzner PA, Waterman M, eds. Research in Computational Molecular Biology. Berlin: Springer, 233-249.

Hutchinson J. 1964. The Genera of Flowering Plants (Docotyledonae). Oxford: Clarendon Press.

Jin J-J. 2019. PersonalUtilities. Available at https://github.com/Kinggerm/PersonalUtilities (accessed 15 Oct 2019 ).

Johnson LB, Palmer JD. 1989. Heteroplasmy of chloroplast DNA in Medicago. Plant Molecular Biology 12:3-11 DOI: $10.1007 / \mathrm{BF} 00017442$.

Katoh K, Standley DM. 2013. MAFFT multiple sequence alignment software version 7: improvements in performance and usability. Molecular Biology and Evolution 30:772-780 DOI: 10.1093/molbev/mst010.

Kishino H, Hasegawa M. 1989. Evaluation of the maximum likelihood estimate of the evolutionary tree topologies from DNA sequence data, and the branching order in hominoidea. Journal of Molecular Evolution 29:170179 DOI: $10.1007 / \mathrm{bf02100115.}$

Koenen EJM, Ojeda DI, Steeves R, Migliore J, Bakker FT, Wieringa JJ, Kidner C, Hardy OJ, Pennington RT, Bruneau A, Hughes CE. 2020. Large-scale genomic sequence data resolve the deepest divergences in the legume phylogeny and support a near-simultaneous evolutionary origin of all six subfamilies. New Phytologist 225:1355-1369 DOI: 10.1111/nph.16290.

Kostermans AJGH. 1957. Lauraceae. Reinwardtia 4:193-256.

Kozlov AM, Darriba D, Flouri T, Morel B, Stamatakis A. 2019. RAxML-NG: a fast, scalable and user-friendly tool for maximum likelihood phylogenetic inference. Bioinformatics 35:4453-4455 DOI: 10.1093/bioinformatics/btz305.

Lanfear R, Frandsen PB, Wright AM, Senfeld T, Calcott B. 2016. PartitionFinder 2: New methods for selecting partitioned models of evolution for molecular and morphological phylogenetic analyses. Molecular Biology and Evolution 34:772-773 DOI: 10.1093/molbev/msw260.

Li H-T, Yi T-S, Gao L-M, Ma P-F, Zhang T, Yang J-B, Gitzendanner MA, Fritsch PW, Cai J, Luo Y, Wang H, van der Bank M, Zhang S-D, Wang Q-F, Wang J, Zhang Z-R, Fu C-N, Yang J, Hollingsworth PM, Chase MW, Soltis DE, Soltis PS, Li D-Z. 2019. Origin of angiosperms and the puzzle of the Jurassic gap. Nature Plants 5:461-470 DOI: 10.1038/s41477-019-0421-0.

Li H-W, Li J, Huang P-H, Wei F-N, Tsui H-P, van der Werff H. 2008a. Lauraceae. In: Wu Z-Y, Raven PH, Hong D-Y, eds. Flora of China. Beijing \& Saint Louis: Science Press \& Missouri Botanical Garden.

Li H, Durbin R. 2010. Fast and accurate long-read alignment with Burrows-Wheeler transform. Bioinformatics 26:589-595 DOI: 10.1093/bioinformatics/btp698.

Peer) reviewing PDF | (2020:05:49532:2:0:NEW 3 Sep 2020) 
Li H, Handsaker B, Wysoker A, Fennell T, Ruan J, Homer N, Marth G, Abecasis G, Durbin R, Subgroup GPDP. 2009. The Sequence Alignment/Map format and SAMtools. Bioinformatics 25:2078-2079 DOI: 10.1093/bioinformatics/btp352.

Li J, Christophel DC, Conran JG, Li H-W. 2004. Phylogenetic relationships within the 'core' Laureae (Litsea complex, Lauraceae) inferred from sequences of the chloroplast gene matK and nuclear ribosomal DNA ITS regions. Plant Systematics and Evolution 246:19-34 DOI: 10.1007/s00606-003-0113-z.

Li J, Conran JG, Christophel DC, Li Z-M, Li L, Li H-W. 2008b. Phylogenetic relationships of the Litsea complex and core Laureae (Lauraceae) using ITS and ETS sequences and morphology. Annals of the Missouri Botanical Garden 95:580-600 DOI: 10.3417/2006125.9504.

Li L, Li J, Conran JG, Li H-W. 2007. Phylogeny of Neolitsea (Lauraceae) inferred from Bayesian analysis of nrDNA ITS and ETS sequences. Plant Systematics and Evolution 269:203-221 DOI: 10.1007/s00606-0070580-8.

Liao Q, Ye T, Song Y. 2018. Complete chloroplast genome sequence of a subtropical tree, Parasassafras confertiflorum (Lauranceae). Mitochondrial DNA Part B 3:1216-1217 DOI: 10.1080/23802359.2018.1532331.

Liu L, Xi Z, Davis CC. 2014. Coalescent methods are robust to the simultaneous effects of long branches and incomplete lineage sorting. Molecular Biology and Evolution 32:791-805 DOI: 10.1093/molbev/msu331.

Liu Z-F, Ci X-Q, Li L, Li H-W, Conran JG, Li J. 2017. DNA barcoding evaluation and implications for phylogenetic relationships in Lauraceae from China. PLOS ONE 12:e0175788 DOI: 10.1371/journal.pone.0175788.

Lohse M, Drechsel O, Kahlau S, Bock R. 2013. OrganellarGenomeDRAW—a suite of tools for generating physical maps of plastid and mitochondrial genomes and visualizing expression data sets. Nucleic Acids Research 41:W575-W581.

Maddison WP. 1997. Gene Trees in Species Trees. Systematic Biology 46:523-536 DOI: 10.1093/sysbio/46.3.523.

Marshall HD, Newton C, Ritland K. 2001. Sequence-repeat polymorphisms exhibit the signature of recombination in Lodgepole pine chloroplast DNA. Molecular Biology and Evolution 18:2136-2138 DOI: 10.1093/oxfordjournals.molbev.a003757.

Mirarab S, Bayzid MS, Warnow T. 2014. Evaluating summary methods for multilocus species tree estimation in the presence of incomplete lineage sorting. Systematic Biology 65:366-380 DOI: 10.1093/sysbio/syu063.

Nayak S, Nalabothu P, Sandiford S, Bhogadi V, Adogwa A. 2006. Evaluation of wound healing activity of Allamanda cathartica L. and Laurus nobilis L. extracts on rats. BMC Complementary and Alternative Medicine 6:12 DOI: 10.1186/1472-6882-6-12.

Nguyen L-T, Schmidt HA, von Haeseler A, Minh BQ. 2014. IQ-TREE: a fast and effective stochastic algorithm for estimating maximum-likelihood phylogenies. Molecular Biology and Evolution 32:268-274 DOI: 10.1093/molbev/msu300.

Nie Z-L, Wen J, Sun H. 2007. Phylogeny and biogeography of Sassafras (Lauraceae) disjunct between eastern Asia and eastern North America. Plant Systematics and Evolution 267:191-203 DOI: 10.1007/s00606-007-05501.

Oldenburg DJ, Bendich AJ. 2016. The linear plastid chromosomes of maize: terminal sequences, structures, and implications for DNA replication. Current Genetics 62:431-442 DOI: 10.1007/s00294-015-0548-0.

Palmer JD. 1985. Comparative organization of chloroplast genomes. Annual Review of Genetics 19:325-354 DOI: 
10.1146/annurev.ge.19.120185.001545.

Parks M, Cronn R, Liston A. 2009. Increasing phylogenetic resolution at low taxonomic levels using massively parallel sequencing of chloroplast genomes. BMC Biology 7:84 DOI: 10.1186/1741-7007-7-84.

Petit RJ, Hampe A. 2006. Some evolutionary consequences of being a tree. Annual Review of Ecology, Evolution, and Systematics 37:187-214 DOI: 10.1146/annurev.ecolsys.37.091305.110215.

Piot A, Hackel J, Christin P-A, Besnard G. 2018. One-third of the plastid genes evolved under positive selection in PACMAD grasses. Planta 247:255-266 DOI: 10.1007/s00425-017-2781-x.

R Core Team. 2018. R: A language and environment for statistical computing. Available at http://www.Rproject.org/ (accessed 12 Dec 2019).

Reboud X, Zeyl C. 1994. Organelle inheritance in plants. Heredity 72:132-140 DOI: 10.1038/hdy.1994.19.

Rohwer JG, Rudolph B. 2005. Jumping genera: the phylogenetic positions of Cassytha, Hypodaphnis, and Neocinnamomum (Lauraceae) based on different analyses of trnK intron sequences. Annals of the Missouri Botanical Garden 1:153-178.

Rohwer JG, Trofimov D, Mayland-Quellhorst E, Albach D. 2019. Incongruence of morphological determinations and DNA barcode sequences: a case study in Cinnamomum (Lauraceae). Willdenowia 49:383-400 DOI: 10.3372/wi.49.49309.

Ruhlman TA, Zhang J, Blazier JC, Sabir JSM, Jansen RK. 2017. Recombination-dependent replication and gene conversion homogenize repeat sequences and diversify plastid genome structure. American Journal of Botany 104:559-572 DOI: 10.3732/ajb.1600453.

Saarela JM, Burke SV, Wysocki WP, Barrett MD, Clark LG, Craine JM, Peterson PM, Soreng RJ, Vorontsova MS, Duvall MR. 2018. A 250 plastome phylogeny of the grass family (Poaceae): topological support under different data partitions. PeerJ 6:e4299 DOI: 10.7717/peerj.4299.

Sancho R, Cantalapiedra CP, López-Alvarez D, Gordon SP, Vogel JP, Catalán P, Contreras-Moreira B. 2018. Comparative plastome genomics and phylogenomics of Brachypodium: flowering time signatures, introgression and recombination in recently diverged ecotypes. New Phytologist 218:1631-1644 DOI: 10.1111/nph.14926.

Sato JJ, Bradford TM, Armstrong KN, Donnellan SC, Echenique-Diaz LM, Begué-Quiala G, Gámez-Díez J, Yamaguchi N, Truong Nguyen S, Kita M, Ohdachi SD. 2019. Post K-Pg diversification of the mammalian order Eulipotyphla as suggested by phylogenomic analyses of ultra-conserved elements. Molecular Phylogenetics and Evolution 141:106605 DOI: 10.1016/j.ympev.2019.106605.

Sayyari E, Mirarab S. 2016. Fast coalescent-based computation of local branch support from quartet frequencies. Molecular Biology and Evolution 33:1654-1668 DOI: 10.1093/molbev/msw079.

Shen X-X, Hittinger CT, Rokas A. 2017. Contentious relationships in phylogenomic studies can be driven by a handful of genes. Nature Ecology \& Evolution 1:0126 DOI: 10.1038/s41559-017-0126.

Shimodaira H. 2002. An approximately unbiased test of phylogenetic tree selection. Systematic Biology 51:492-508 DOI: $10.1080 / 10635150290069913$.

Shimodaira H, Hasegawa M. 1999. Multiple comparisons of log-likelihoods with applications to phylogenetic inference. Molecular Biology and Evolution 16:1114-1114.

Simmons MP, Kessenich J. 2019. Divergence and support among slightly suboptimal likelihood gene trees. Cladistics DOI: 10.1111/cla.12404.

Smith DR. 2014. Mitochondrion-to-plastid DNA transfer: it happens. New Phytologist 202:736-738 DOI: 
605

606

607

608

609

610

611

612

613

614

615

616

617

618

619

620

621

622

623

624

625

626

627

628

629

630

631

632

633

634

635

636

637

638

639

640

641

642

643

644

645

10.1111/nph.12704.

Song Y, Yu W-B, Tan Y, Jin J, Wang B, Yang J-B, Liu B, Corlett RT. 2019. Plastid phylogenomics improve phylogenetic resolution in the Lauraceae. Journal of Systematics and Evolution DOI: 10.1111/jse.12536.

Song Y, Yu WB, Tan Y, Liu B, Yao X, Jin J, Padmanaba M, Yang JB, Corlett RT. 2017. Evolutionary comparisons of the chloroplast genome in Lauraceae and insights into loss events in the Magnoliids. Genome Biology and Evolution 9:2354-2364 DOI: 10.1093/gbe/evx180.

Springer MS, Gatesy J. 2016. The gene tree delusion. Molecular Phylogenetics and Evolution 94:1-33 DOI: 10.1016/j.ympev.2015.07.018.

Stamatakis A. 2014. RAxML version 8: a tool for phylogenetic analysis and post-analysis of large phylogenies. Bioinformatics 30:1312-1313 DOI: 10.1093/bioinformatics/btu033.

Stegemann S, Hartmann S, Ruf S, Bock R. 2003. High-frequency gene transfer from the chloroplast genome to the nucleus. Proceedings of the National Academy of Sciences of the United States of America 100:8828 DOI: 10.1073/pnas.1430924100.

Sullivan AR, Schiffthaler B, Thompson SL, Street NR, Wang X-R. 2017. Interspecific plastome recombination reflects ancient reticulate evolution in Picea (Pinaceae). Molecular Biology and Evolution 34:1689-1701 DOI: $10.1093 / \mathrm{molbev} / \mathrm{msx} 111$.

Sun M, Soltis DE, Soltis PS, Zhu X, Burleigh JG, Chen Z. 2015. Deep phylogenetic incongruence in the angiosperm clade Rosidae. Molecular Phylogenetics and Evolution 83:156-166 DOI: 10.1016/j.ympev.2014.11.003.

Szmidt AE, Aldén T, Hällgren J-E. 1987. Paternal inheritance of chloroplast DNA in Larix. Plant Molecular Biology 9:59-64 DOI: 10.1007/BF00017987.

Tian X, Ye J, Song Y. 2019. Plastome sequences help to improve the systematic position of trinerved Lindera species in the family Lauraceae. PeerJ 7:e7662 DOI: 10.7717/peerj.7662.

Tillich M, Lehwark P, Pellizzer T, Ulbricht-Jones ES, Fischer A, Bock R, Greiner S. 2017. GeSeq - versatile and accurate annotation of organelle genomes. Nucleic Acids Research 45:W6-W11 DOI: 10.1093/nar/gkx391.

van der Werff H. 1984. Notes on neotropical Lauraceae. Annals of the Missouri Botanical Garden 71:1180-1183 DOI: $10.2307 / 2399252$.

van der Werff H, Richter HG. 1996. Toward an improved classification of Lauraceae. Annals of the Missouri Botanical Garden 83:409-418 DOI: 10.2307/2399870.

Walker JF, Walker-Hale N, Vargas OM, Larson DA, Stull GW. 2019. Characterizing gene tree conflict in plastomeinferred phylogenies. PeerJ 7:e7747 DOI: 10.7717/peerj.7747.

Wang G, Zhao C, Chen Y, Cheng C, Zhao Y. 2009. National key protected plant flora and distribution characteristic in Zhoushan Islands. Journal of Zhejiang Forestry Science and Technology 29:43-47.

Wicke S, Schneeweiss GM, dePamphilis CW, Müller KF, Quandt D. 2011. The evolution of the plastid chromosome in land plants: gene content, gene order, gene function. Plant Molecular Biology 76:273-297 DOI: $10.1007 / \mathrm{s} 11103-011-9762-4$.

Wickham H. 2016. ggplot2: elegant graphics for data analysis. New York: Springer-Verlag.

Wikström N, Bremer B, Rydin C. 2020. Conflicting phylogenetic signals in genomic data of the coffee family (Rubiaceae). Journal of Systematics and Evolution DOI: 10.1111/jse.12566.

Wolfe AD, Randle CP. 2004. Recombination, heteroplasmy, haplotype polymorphism, and paralogy in plastid genes: implications for plant molecular systematics. Systematic Botany 29:1011-1020.

Wysocki WP, Clark LG, Attigala L, Ruiz-Sanchez E, Duvall MR. 2015. Evolution of the bamboos (Bambusoideae;

Peer) reviewing PDF | (2020:05:49532:2:0:NEW 3 Sep 2020) 
646

647

648

649

650

651

652

653

654

655

656

657

658

659

660

661

662

663

664

665

666

667

668

669

670

671

672

673
Poaceae): a full plastome phylogenomic analysis. BMC Evolutionary Biology 15:50 DOI: 10.1186/s12862015-0321-5.

Xi Z, Liu L, Davis CC. 2015. Genes with minimal phylogenetic information are problematic for coalescent analyses when gene tree estimation is biased. Molecular Phylogenetics and Evolution 92:63-71 DOI: 10.1016/j.ympev.2015.06.009.

Xi Z, Ruhfel BR, Schaefer H, Amorim AM, Sugumaran M, Wurdack KJ, Endress PK, Matthews ML, Stevens PF, Mathews S, Davis CC. 2012. Phylogenomics and a posteriori data partitioning resolve the Cretaceous angiosperm radiation Malpighiales. Proceedings of the National Academy of Sciences of the United States of America 109:17519-17524 DOI: 10.1073/pnas.1205818109.

Xu W-Q, Losh J, Chen C, Li P, Wang R-H, Zhao Y-P, Qiu Y-X, Fu C-X. 2019. Comparative genomics of figworts (Scrophularia, Scrophulariaceae), with implications for the evolution of Scrophularia and Lamiales. Journal of Systematics and Evolution 57:55-65 DOI: 10.1111/jse.12421.

Yang Z. 2007. PAML 4: Phylogenetic Analysis by Maximum Likelihood. Molecular Biology and Evolution 24:1586-1591 DOI: 10.1093/molbev/msm088.

Yu XQ, Gao LM, Soltis DE, Soltis PS, Yang JB, Fang L, Yang SX, Li DZ. 2017. Insights into the historical assembly of East Asian subtropical evergreen broadleaved forests revealed by the temporal history of the tea family. New Phytologist 215:1235-1248 DOI: doi:10.1111/nph.14683.

Zhang C, Rabiee M, Sayyari E, Mirarab S. 2018. ASTRAL-III: polynomial time species tree reconstruction from partially resolved gene trees. BMC Bioinformatics 19:153 DOI: 10.1186/s12859-018-2129-y.

Zhang R, Wang Y-H, Jin J-J, Stull GW, Bruneau A, Cardoso D, de Queiroz LP, Moore MJ, Zhang S-D, Chen S-Y, Wang J, Li D-Z, Yi T-S. 2020. Exploration of plastid phylogenomic conflict yields new insights into the deep relationships of Leguminosae. Systematic Biology DOI: 10.1093/sysbio/syaa013.

Zhao L, Li X, Zhang N, Zhang S-D, Yi T-S, Ma H, Guo Z-H, Li D-Z. 2016. Phylogenomic analyses of large-scale nuclear genes provide new insights into the evolutionary relationships within the rosids. Molecular Phylogenetics and Evolution 105:166-176 DOI: 10.1016/j.ympev.2016.06.007.

Zhao M-L, Song Y, Ni J, Yao X, Tan Y-H, Xu Z-F. 2018. Comparative chloroplast genomics and phylogenetics of nine Lindera species (Lauraceae). Scientific Reports 8:8844 DOI: 10.1038/s41598-018-27090-0. 


\section{Table $\mathbf{1}$ (on next page)}

Sampled species and voucher specimens of Laureae in this study. 


\begin{tabular}{|c|c|c|c|c|}
\hline Taxon & Herbarium & Voucher & Geographic origin & $\begin{array}{l}\text { GenBank } \\
\text { Accession } \\
\text { number }\end{array}$ \\
\hline $\begin{array}{l}\text { Actinodaphne obovata } \\
\text { (Nees) Bl. }\end{array}$ & IBSC & XTBGLQM0236 & $\begin{array}{l}\text { Xishuangbanna, Yunnan, } \\
\text { China }\end{array}$ & MN274947 \\
\hline $\begin{array}{l}\text { Iteadaphne caudata } \\
\text { (Nees) H. W. Li }\end{array}$ & IBSC & XTBGLQM0582 & $\begin{array}{l}\text { Xishuangbanna, Yunnan, } \\
\text { China }\end{array}$ & MN428456 \\
\hline $\begin{array}{l}\text { Lindera erythrocarpa } \\
\text { Makino }\end{array}$ & IBSC & 180923 & $\begin{array}{l}\text { Baishanzu Mountain, } \\
\text { Zhejiang, China }\end{array}$ & MN428457 \\
\hline Litsea acutivena Hay. & 1 & 1 & $\begin{array}{l}\text { Chebaling, Guangdong, } \\
\text { China }\end{array}$ & MN428458 \\
\hline $\begin{array}{l}\text { Litsea dilleniifolia } \mathrm{P} . \mathrm{Y} \text {. } \\
\text { Pai et P. H. Huang }\end{array}$ & IBSC & XTBGLQM0095 & $\begin{array}{l}\text { Xishuangbanna, Yunnan, } \\
\text { China }\end{array}$ & MN428459 \\
\hline $\begin{array}{l}\text { Litsea elongata (Wall. ex } \\
\text { Nees) Benth. et Hook. f. }\end{array}$ & IBSC & WBGQXJ001 & $\begin{array}{l}\text { Badagong Mountain, } \\
\text { Hunan, China }\end{array}$ & MN428460 \\
\hline $\begin{array}{l}\text { Litsea glutinosa (Lour.) } \\
\text { C. B. Rob. }\end{array}$ & IBSC & XTBGLQM0653 & $\begin{array}{l}\text { Xishuangbanna, Yunnan, } \\
\text { China }\end{array}$ & MN428461 \\
\hline Litsea mollis Hemsl. & IBSC & CFL2678 & $\begin{array}{l}\text { Libo county, Guizhou, } \\
\text { China }\end{array}$ & MN428462 \\
\hline $\begin{array}{l}\text { Litsea monopetala } \\
\text { (Roxb.) Pers. }\end{array}$ & IBSC & XTBGLQM0687 & $\begin{array}{l}\text { Xishuangbanna, Yunnan, } \\
\text { China }\end{array}$ & MN428463 \\
\hline Litsea pungens Hemsl. & IBSC & WBGQXJ124 & $\begin{array}{l}\text { Badagong Mountain, } \\
\text { Hunan, China }\end{array}$ & MN428464 \\
\hline $\begin{array}{l}\text { Litsea szemaois (H. Liu) } \\
\text { J. Li et H.W. Li }\end{array}$ & IBSC & XTBGLQM0692 & $\begin{array}{l}\text { Xishuangbanna, Yunnan, } \\
\text { China }\end{array}$ & MN428465 \\
\hline $\begin{array}{l}\text { Neolitsea pallens (D. } \\
\text { Don) Momiy. et H. Hara }\end{array}$ & IBSC & 18371 & $\begin{array}{l}\text { Dinghu Mountain, } \\
\text { Guangdong, China }\end{array}$ & MN428466 \\
\hline
\end{tabular}


Table 2 (on next page)

Summary of 12 complete plastomes of Laureae. 
1

\begin{tabular}{|c|c|c|c|c|c|c|}
\hline & $\begin{array}{c}\text { Actinodaphne } \\
\text { obovata }\end{array}$ & $\begin{array}{c}\text { Iteadaphne } \\
\text { caudata }\end{array}$ & $\begin{array}{c}\text { Lindera } \\
\text { erythrocarpa }\end{array}$ & $\begin{array}{c}\text { Litsea } \\
\text { acutivena }\end{array}$ & $\begin{array}{c}\text { Litsea } \\
\text { elongata }\end{array}$ & $\begin{array}{c}\text { Litsea } \\
\text { glutinosa }\end{array}$ \\
\hline Total cpDNA size (bp) & 152579 & 152863 & 152916 & 152718 & 152793 & 152748 \\
\hline Length of LSC region (bp) & 93655 & 93761 & 93921 & 93677 & 93827 & 93698 \\
\hline Length of IR region (bp) & 20057 & 20144 & 20071 & 20066 & 20066 & 20062 \\
\hline Length of SSC region (bp) & 18810 & 18814 & 18853 & 18909 & 18844 & 18926 \\
\hline Total GC content $(\%)$ & 39.1 & 39.1 & 39.1 & 39.2 & 39.1 & 39.2 \\
\hline LSC GC content (\%) & 37.9 & 38.0 & 37.9 & 38.0 & 37.9 & 38.0 \\
\hline IR GC content $(\%)$ & 44.4 & 44.4 & 44.4 & 44.4 & 44.4 & 44.5 \\
\hline SSC GC content $(\%)$ & 33.9 & 33.8 & 34.0 & 33.9 & 33.9 & 33.8 \\
\hline Total number of genes (unique) & $127(112)$ & $127(112)$ & $127(112)$ & $127(112)$ & $127(112)$ & $127(112)$ \\
\hline Protein-coding genes (unique) & $84(78)$ & $84(78)$ & $84(78)$ & $84(78)$ & $84(78)$ & $84(78)$ \\
\hline Total number of tRNA & $36(30)$ & $36(30)$ & $36(30)$ & $36(30)$ & $36(30)$ & $36(30)$ \\
\hline Total number of rRNA & $8(4)$ & $8(4)$ & $8(4)$ & $8(4)$ & $8(4)$ & $8(4)$ \\
\hline \multicolumn{7}{|l|}{2} \\
\hline & $\begin{array}{c}\text { Litsea } \\
\text { dilleniifolia }\end{array}$ & Litsea mollis & $\begin{array}{c}\text { Litsea } \\
\text { monopetala }\end{array}$ & $\begin{array}{c}\text { Litsea } \\
\text { pungens }\end{array}$ & $\begin{array}{c}\text { Litsea } \\
\text { szemaois }\end{array}$ & $\begin{array}{c}\text { Neolitsea } \\
\text { pallens }\end{array}$ \\
\hline Total cpDNA size (bp) & 152298 & 152736 & 152705 & 152655 & 152132 & 152699 \\
\hline Length of LSC region (bp) & 93218 & 93655 & 93758 & 93520 & 93119 & 93761 \\
\hline Length of IR region (bp) & 20094 & 20063 & 20074 & 20131 & 20090 & 20071 \\
\hline Length of SSC region (bp) & 18892 & 18936 & 18799 & 18873 & 18843 & 18796 \\
\hline Total GC content $(\%)$ & 39.2 & 39.2 & 39.2 & 39.2 & 39.2 & 39.1 \\
\hline LSC GC content (\%) & 38.0 & 38.0 & 38.0 & 37.9 & 38.1 & 37.9 \\
\hline IR GC content $(\%)$ & 44.4 & 44.4 & 44.4 & 44.4 & 44.4 & 44.4 \\
\hline SSC GC content $(\%)$ & 34.0 & 33.9 & 33.9 & 34.0 & 34.0 & 33.9 \\
\hline Total number of genes (unique) & $127(112)$ & $127(112)$ & $127(112)$ & $\begin{array}{c}127 \\
(112)\end{array}$ & $\begin{array}{c}127 \\
(112)\end{array}$ & $127(112)$ \\
\hline Protein-coding genes (unique) & $84(78)$ & $84(78)$ & $84(78)$ & $84(78)$ & $84(78)$ & $84(78)$ \\
\hline Total number of tRNA & $36(30)$ & $36(30)$ & $36(30)$ & $36(30)$ & $36(30)$ & $36(30)$ \\
\hline Total number of rRNA & $8(4)$ & $8(4)$ & $8(4)$ & $8(4)$ & $8(4)$ & $8(4)$ \\
\hline
\end{tabular}

3 
Figure 1

Complete plastid genome map of Laureae.

Different functional genes are color coded. Genes outside the circle are transcribed counterclockwise, genes inside the circle are transcribed clockwise. GC content is indicated by darker gray in the inner circle. 


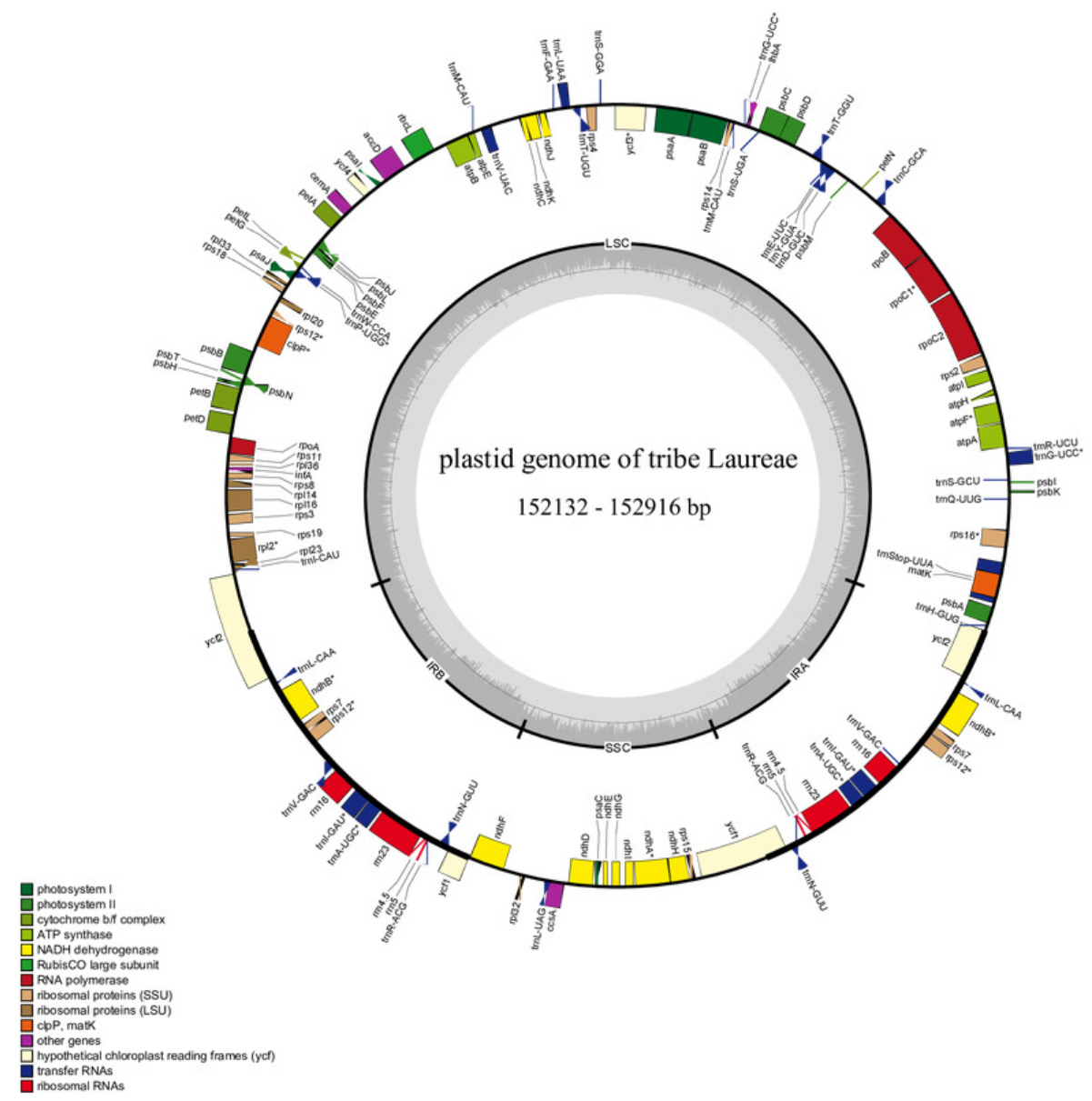


Figure 2

Maximum likelihood phylogenetic tree of Laureae inferred with RAxML-NG based on complete plastomes.

Bootstrap values are indicated on branches. Subclades I, II and III are colored in red, green and blue, respectively. 

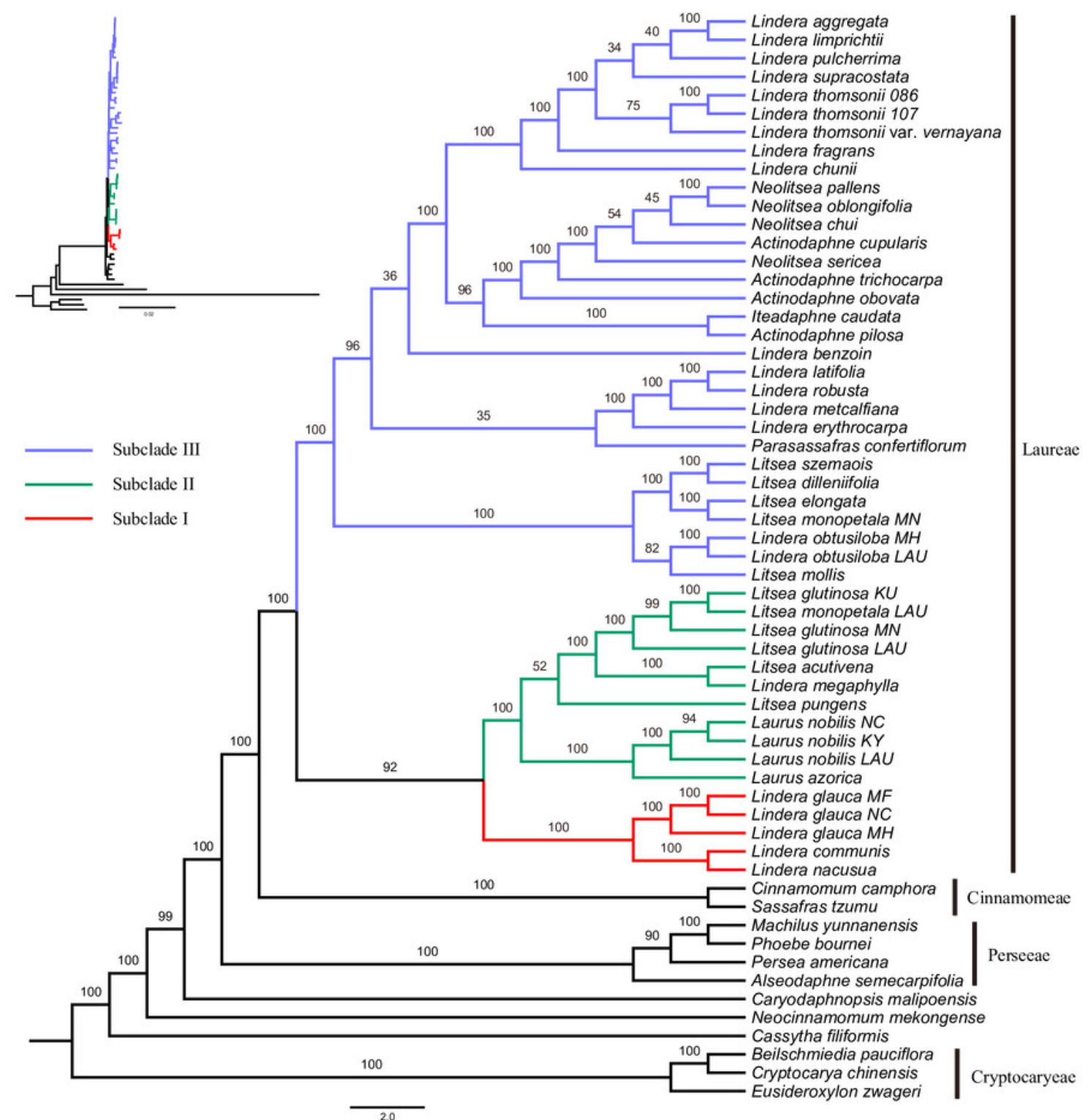
Figure 3

Tree of Laureae inferred with ASTRAL III using a multispecies coalescent approach.

Local posterior probabilities (LPP) are indicated on branches. Subclades I, II and III are colored in red, green and blue, respectively. 


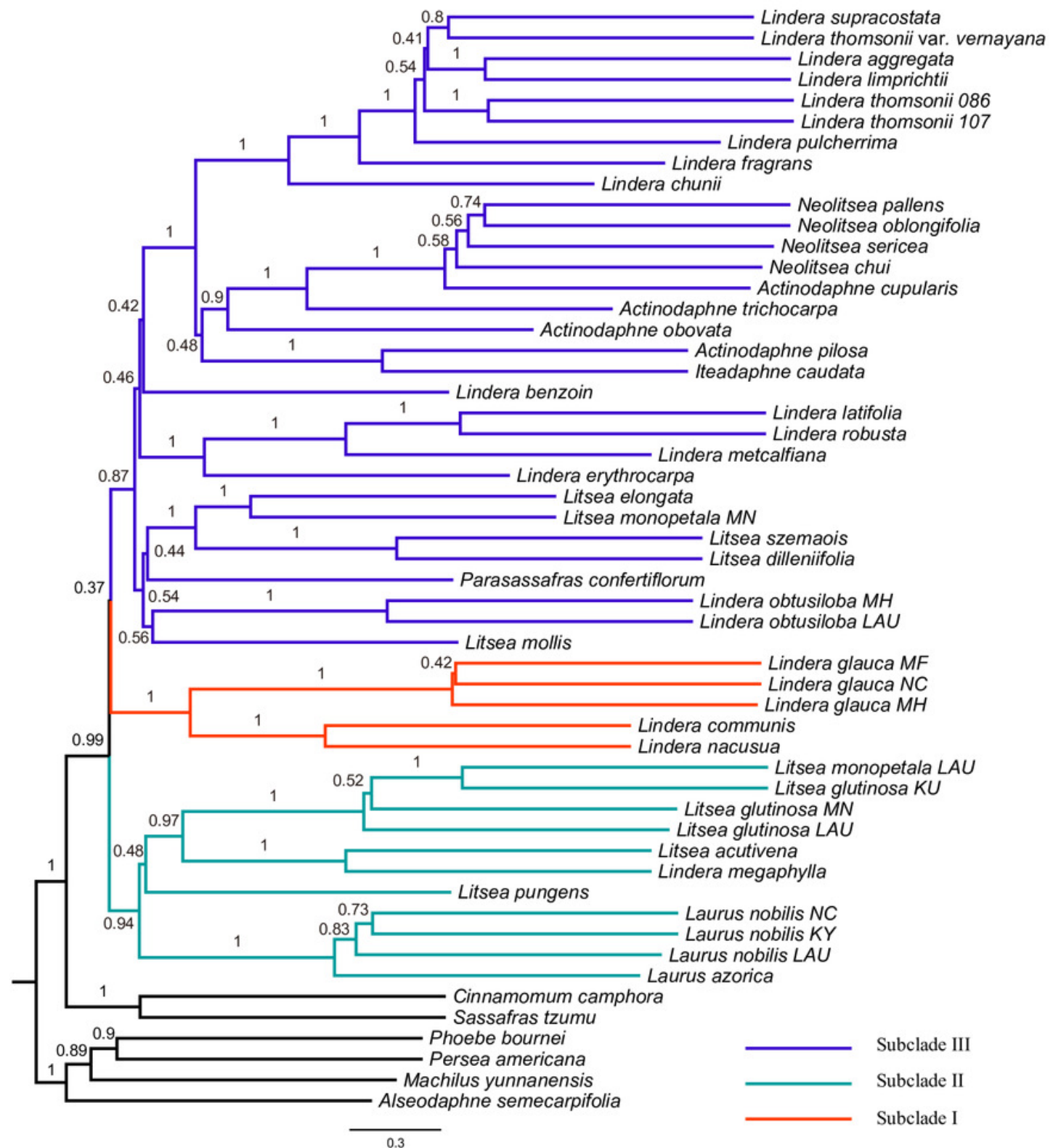




\section{Figure 4}

Difference in the log-likelihood ( $\mathrm{InL}$ ) of each plastid locus between two alternative topologies.

The $x$ axis indicates each locus, and the $y$ axis indicates $\operatorname{lnL}$ difference. (A) Positive and negative values support the topology showing subclades I-II (T1) and subclades II-III (T2), respectively. (B) Positive and negative values support the topology showing subclades I-II (T1) and subclades I-III (T3), respectively. (C) Positive and negative values support the topology showing subclades II-III (T2) and subclades I-III (T3), respectively. Values starting with + or - indicate the sum of positive and negative values, respectively, and the number of supporting loci is shown in the parenthesis. Note that the order of loci on $x$ axis are different among $A, B$ and $C$. 

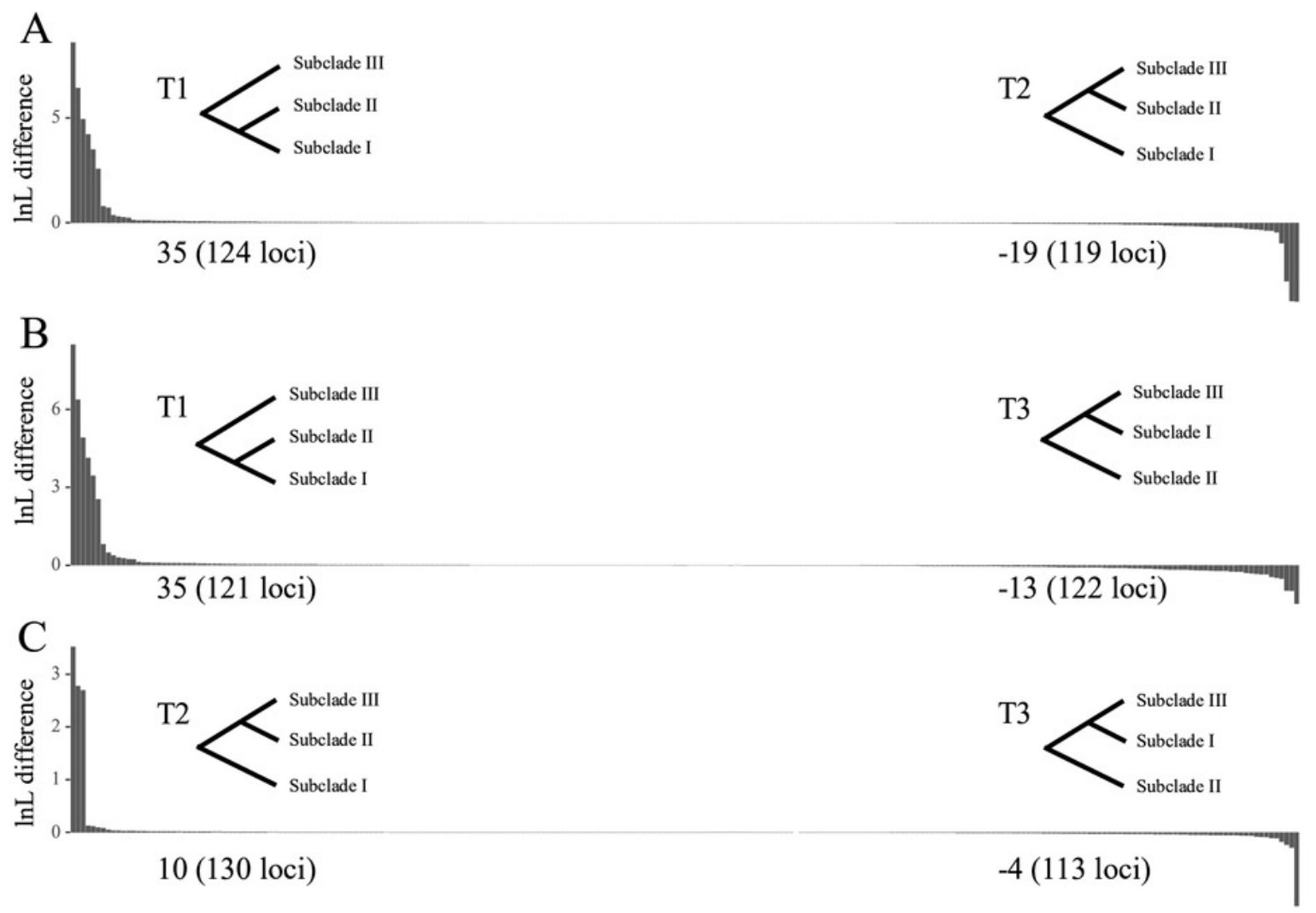